\title{
Влияние „объема“ активной среды на излучательные свойства лазерных гетероструктур с выходом излучения через подложку
}

\author{
(C) С.М. Некоркин ${ }^{1}$, Б.Н. Звонков ${ }^{1}$, Н.В. Байдусь ${ }^{1}$, Н.В. Дикарева ${ }^{1, \pi,}$ \\ О.В. Вихрова ${ }^{1}$, А.А. Афоненко ${ }^{2}$, Д.В. Ушаков ${ }^{2}$ \\ ${ }^{1}$ Научно-исследовательский фризико-технический институт \\ Нижегородского государственного университета им. Н.И. Лобачевского, \\ 603950 Нижний Новгород, Россия \\ ${ }^{2}$ Белорусский государственный университет, \\ 220030 Минск, Республика Беларусь \\ ฯ E-mail: dnat@ro.ru
}

(Получена 5 апреля 2016 г. Принята к печати 12 апреля 2016 г.)

Исследованы излучательные свойства лазерных структур InGaAs/GaAs/InGaP с вытеканием излучения через подложку в зависимости от числа квантовых ям в активной области и лазерных диодов на их основе. Установлено, что наличие 6-8 квантовых ям в активной области является оптимальным с точки зрения наблюдаемых значений порогового тока и выходной оптической мощности лазеров.

DOI: 10.21883/FTP.2017.01.43999.8258

\section{1. Введение}

Полупроводниковые лазеры со значительным вытеканием излучения через подложку - одни из перспективных источников когерентного излучения повышенной мощности [1], но пороговый ток таких лазеров увеличен за счет больших полезных потерь на вытекание в подложку. Поэтому для увеличения коэффициента усиления необходимо в активную область лазера встраивать большее количество квантовых ям (КЯ) [2]. Однако вопрос об оптимальном „объеме“ активной среды остается открытым из-за влияния на параметры выходного излучения лазеров многих факторов, таких, как конкуренция мод внутри лазерного волновода [3], температурная стабильность порогового тока [4] и др.

В связи с этим целью данной работы является исследование излучательных свойств лазерных структур $\mathrm{InGaAs} / \mathrm{GaAs} / \mathrm{InGaP}$ со значительным выходом излучения через подложку в зависимости от числа ям в активной области и сопоставление полученных результатов с параметрами готовых лазерных диодов.

\section{2. Методика эксперимента}

Исследуемые структуры были выращены методом МOC-гидридной эпитаксии в горизонтальном реакторе при атмосферном давлении на подложках $n^{+}$-GaAs (100) и содержали 4, 6, 8 или 10 квантовых ям в активной области. Структуры выращивались при температурах $620-650^{\circ} \mathrm{C}$ на подложках $n^{+}$-GaAs (100). Они включали в себя буферный $n^{+}$-GaAs и контактный $p^{+}$-GaAs слои, нижний $n$-InGaP и верхний $p$-InGaP ограничивающие слои, волновод $\mathrm{GaAs} \sim 1800$ нм и активную область, содержащую несколько квантовых ям $\operatorname{In}_{x} \mathrm{Ga}_{1-x}$ As шириной 10 нм $(x=0.15 \pm 0.017)$, разделенных барьерами $\mathrm{GaAs} / \mathrm{GaAsP}$ толщиной $50 \pm 8$ нм (содержание фосфора в барьерах GaAsP не превышало 20\%). Слои GaAsP были введены в структуру для компенсации напряжений сжатия, присутствующих в квантовых ямах $\operatorname{In}_{x} \mathrm{Ga}_{1-x} \mathrm{As}$. Параметры компенсирующих слоев для всех структур были одинаковые.

Оптическое качество структур исследовалось методом спектроскопии фотолюминесценции при температурах 77 и $300 \mathrm{~K}$. Излучение возбуждалось $\mathrm{He}-\mathrm{Ne}$-лазером (632.5 нм) мощностью 30 мВт. Анализировались спектры фотолюминесценции активной области структур.

На основе выращенных гетероструктур изготавливались лазерные диоды с шириной активной области 360 мкм и длиной резонатора 1 мм. Напыления просветляющих и отражающих покрытий на грани лазерных чипов не проводились. Зеркалами служили сколотые грани структур. Энергетические характеристики изготовленных лазерных диодов измерялись при накачке одиночными импульсами тока длительностью 5 мкс.

\section{3. Численное моделирование}

Расчеты мощностных характеристик проводились на основе диффузионно-дрейфовой модели [5], дополнительно учитывающей поглощение излучения свободными носителями и изменение длины волны генерации в зависимости от температуры и уровня возбуждения структуры. Характеристики лазера в произвольный момент времени $t$ считались зависящими от температуры $T(t)$ и находились с помощью линейной интерполяции. Так, например, плотность фотонов вычислялась как

$$
S(T)=S\left(T_{0}\right)+\frac{S\left(T_{1}\right)-S\left(T_{0}\right)}{T_{1}-T_{0}}\left(T-T_{0}\right) .
$$

Здесь величины $S\left(T_{0}\right)$ и $S\left(T_{1}\right)$ рассчитывались при соответствующих температурах. Это позволило использовать ранее разработанную модель [5] без включения в систему базовых уравнений динамического уравне- 
ния для температуры. Выходные характеристики лазера усреднялись по времени действия импульса накачки.

Изменение температуры активной области после включения тока накачки находилось с использованием формализма функции Грина:

$$
T(t)-T_{0}=\int_{0}^{t} G(\tau) w_{\text {heat }}(t-\tau) d \tau .
$$

Такой подход обоснован тем, что за время действия импульса $\tau$ эффективное расстояние, на которое успевает распространиться тепло от точечного источника в $\mathrm{GaAs}$, составляет $\sim 2 \sqrt{\chi \tau}=22$ мкм $(\chi-$ коэффициент температуропроводности). Оно многократно превышает толщину активной области, но много меньше толщины подложки и теплоотвода. Аналитический вид функции Грина легко получить в приближении однородного материала

$$
G(\tau)=\frac{\gamma}{2 \rho c_{p} \sqrt{\pi \chi \tau}}
$$

где $\rho-$ плотность, $c_{p}-$ теплоемкость материала. В расчетах для указанных величин использовались параметры GaAs. Особенности теплопередачи реальной структуры, включающей слои оптического ограничения InGaP, припоя и теплоотвода, учитывались с помощью подгоночного множителя $\gamma$. Мощность источников тепла на единичную площадь включала подведенную электрическую мощность, уменьшенную на мощность излучения, выходящего из резонатора на его гранях и вытекающего в подложку:

$$
w_{\text {heat }}(t)=j(t) U(t)-S(t) v_{g}\left(\rho_{\text {ext }}+\rho_{\text {leak }}\right) \hbar \omega(t),
$$

где $j, U-$ плотность тока и напряжение на структуре (без учета подложки), $S$ - двухмерная плотность фотонов в волноводе, $\hbar \omega-$ энергия квантов излучения, $v_{g}$ - групповая скорость света, $\rho_{\text {ext }}$ и $\rho_{\text {leak }}-$ коэффициенты внешних потерь и потерь в вытекающую моду. Плотность фотонов в вытекающей моде считалась как

$$
S_{\text {leak }}=S \frac{\rho_{\text {leak }}}{\rho_{\text {ext }}+\rho_{\text {sub }}},
$$

где $\rho_{\text {sub }}$ - коэффициент поглощения вытекающей моды в подложке.

\section{4. Фотолюминесценция лазерных структур}

Спектры фотолюминесценции лазерных структур с различным количеством квантовых ям в активной области, измеренные при температуре $77 \mathrm{~K}$, приведены на рис. 1. Наблюдается небольшое возрастание сигнала фотолюминесценции при увеличении количества квантовых ям с 4 до 8 и резкое возрастание интенсивности сигнала в гетероструктурах с 10 квантовыми ямами в активной области. Вероятно, низкая температура измерений препятствует термической делокализации носителей заряда, и увеличение интенсивности связано с увели-

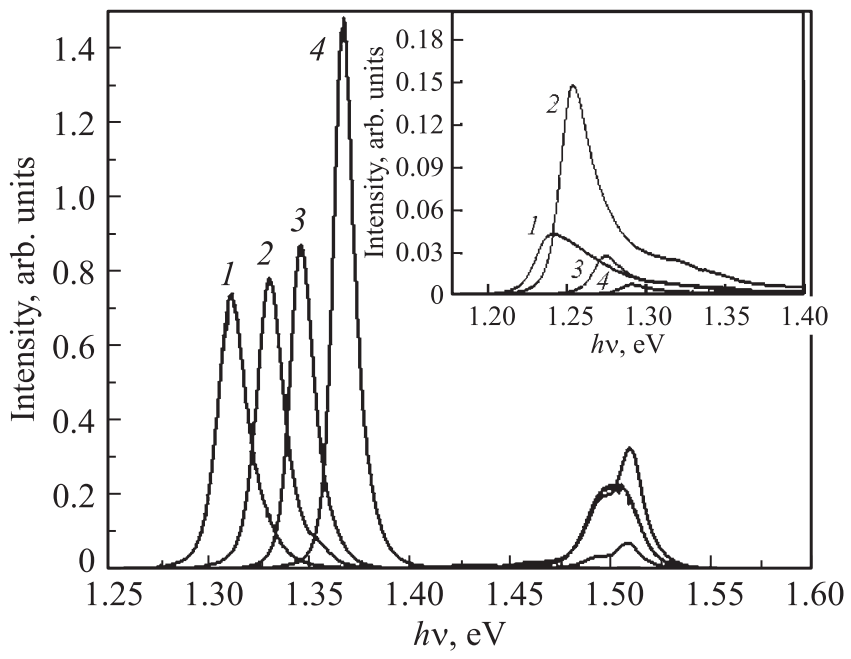

Рис. 1. Спектры фотолюминесценции лазерных структур, содержащих различное количество квантовых ям в активной области при температуре 77 и $300 \mathrm{~K}$ (на вставке). Кривая $1-4$ квантовые ямы в активной области, $2-6,3-8$, $4-10$ КЯ.

чением собирания генерированных светом электроннодырочных пар.

При комнатной температуре $(300 \mathrm{~K})$ наибольшая интенсивность фотолюминесценции соответствует активной области, содержащей 6 квантовых ям (см. вставку на рис. 1). Уменьшение количества квантовых ям до 4 или увеличение до 8-10 приводит к значительному гашению сигнала фотолюминесценции. Возможно, в первом случае интенсивность фотолюминесценции невысока из-за неполного собирания электронно-дырочных пар в квантовых ямах. Для случая 8 или 10 квантовых ям, по-видимому, повышается дефектность активной области, а вследствие этого возрастает вклад безызлучательной рекомбинации и уменьшается интенсивность фотолюминесценции при высокой температуре измерений.

Следует отметить особенность, наблюдаемую на рис. 1: количество ям в активной области также влияет на спектральное положение пика фотолюминесценции активной области. При этом структурам с 4 квантовыми ямами соответствуют более длинноволновые пики в спектре фотолюминесценции, а структурам с 8 и 10 ямами - более коротковолновые по отношению к спектральному положению сигнала фотолюминесценции активной области структур с 6 квантовыми ямами.

Наблюдаемый эффект влияния количества квантовых ям на энергию максимума фотолюминесцентного излучения лазерных структур может быть связан с распределением напряжений в активной области, а именно с возрастанием упругих деформаций сжатия при увеличении числа ям и снижением упругих деформаций сжатия с уменьшением числа ям [6].

Таким образом, анализ представленных спектров фотолюминесценции показывает, что число квантовых ям в активной области значительно влияет на излучательные 
свойства многоямной лазерной гетероструктуры. Малый „объем“ активной среды существенно уменьшает эффективность собирания электронно-дырочных пар, а увеличение числа квантовых ям способствует накоплению упругих напряжений, приводя тем самым не только к гашению сигнала фотолюминесценции, но и сдвигу спектрального максимума.

\section{5. Мощностные характеристики лазерных диодов}

Экспериментальные исследования мощностных характеристик лазерных диодов, изготовленных на основе исследуемых структур, показали, что лазеры с выходом излучения через подложку с меньшим числом квантовых ям в активной области имеют низкую мощность излучения и высокие пороговые токи. На рис. 2 приведены зависимости внешней дифференциальной квантовой эффективности (кривая 1 ), порогового тока (кривая 2) и средней мощности излучения полупроводниковых лазерных диодов от числа квантовых ям в активной среде. Так, пороговый ток четырехъямных лазеров составил $50 \pm 0.2 \mathrm{~A}$, а квантовая эффективность не превышала $8 \pm 0.2 \%$. Пороговый ток шестиямных и
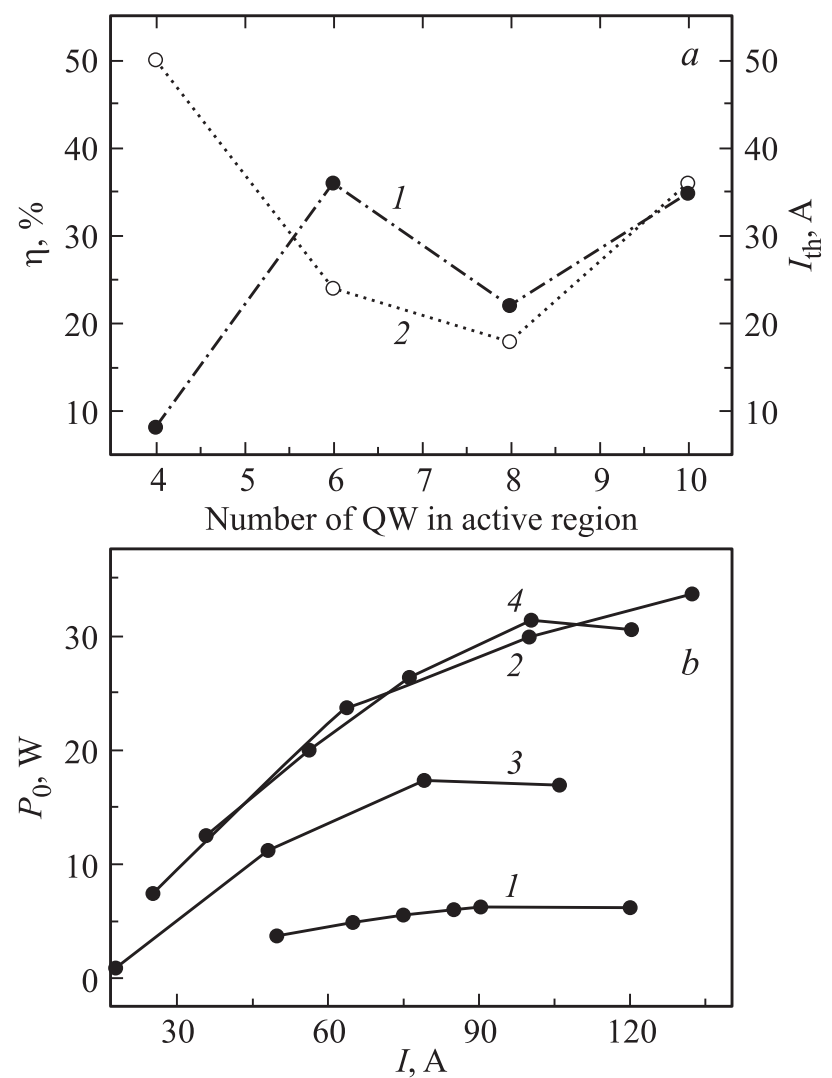

Pис. 2. $a-$ зависимости внешней дифференциальной квантовой эффективности (1), порогового тока (2) и $b-$ зависимости средней мощности излучения полупроводниковых лазерных диодов от числа КЯ в активной среде: $1-4,2-6$, $3-8,4-10$ КЯ. Накачка одиночными импульсами тока длительностью 5 мкс.

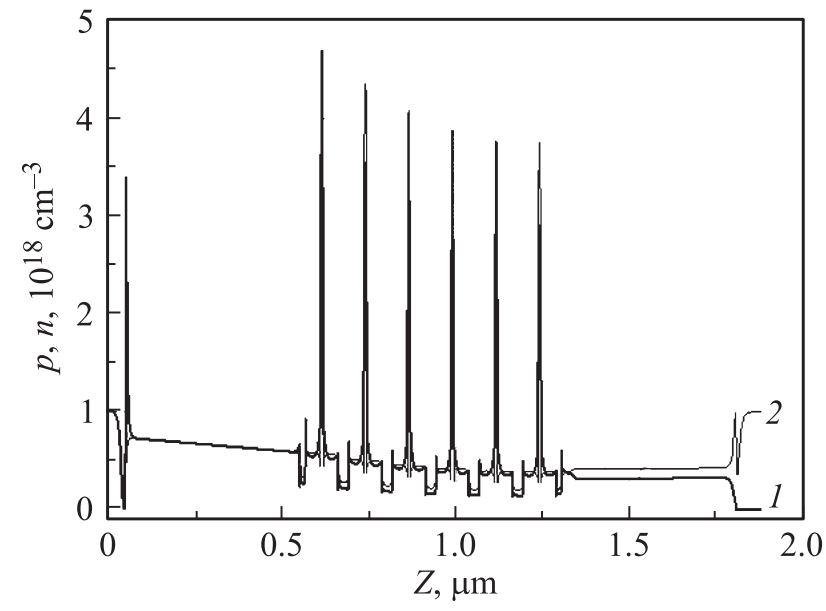

Рис. 3. Распределение концентрации носителей в структуре c 6 квантовыми ямами при лазерной генерации при токе накачки $60 \mathrm{~A}: 1$ - концентрация дырок, 2 - концентрация электронов.

восьмиямных гетеролазеров существенно ниже и составляет 24 и $18 \pm 0.2 \mathrm{~A}$, а квантовая эффективность 36 и $22 \pm 0.2 \%$ соответственно. Пороговые токи и квантовая эффективность гетеролазеров с 10 квантовыми ямами в активной области составляли $36 \pm 0.2 \mathrm{~A}$ и $35 \pm 0.2 \%$ соответственно.

Большой порог генерации и низкие значения квантовой эффективности лазерных диодов с 4 квантовыми ямами в активной области, вероятно, обусловлены близостью предельного коэффициента модового усиления квантовых ям к суммарному коэффициенту потерь волноводной моды, в результате чего для достижения порога генерации происходит значительное заселение не только квантовых ям, но и волноводного слоя.

Снижение квантовой эффективности в лазерных диодах с 8 и 10 квантовыми ямами в активной области может быть связано с возрастающей дефектностью активной среды, что подтверждают спектры высокотемпературной $(300 \mathrm{~K})$ фотолюминесценции, а также с неоднородностью заполнения носителями заряда квантовых ям [7].

Анализ расчетных характеристик лазерных диодов со значительным выходом излучения через подложку также показал, что при прохождении тока через гетероструктуру реализуется неоднородное возбуждение квантовых ям. Это наглядно демонстрирует распределение концентрации носителей в структуре, представленное на рис. 3. Поэтому добавление каждой новой квантовой ямы дает все меньший вклад в результирующее усиление и увеличивает пороговый ток [8]. С другой стороны, наличие значительных потерь вытекающей моды приводит к необходимости создания высокого уровня возбуждения структуры в целом, большой заселенности волноводного слоя $\left(\sim 5 \cdot 10^{17} \mathrm{~cm}^{-3}\right)$. В результате вносятся дополнительные потери поглощения свободными носителями и создается дополнительный нагрев активной области. 

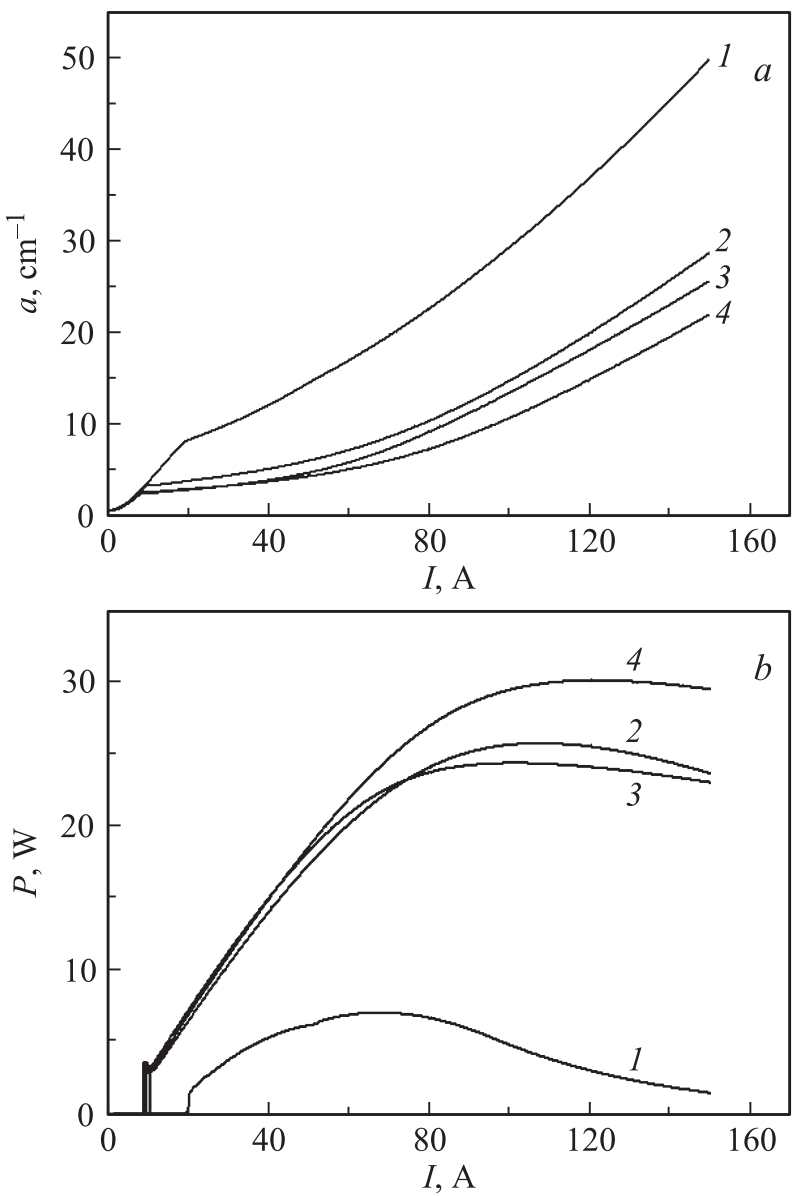

Рис. 4. Расчетные зависимости $(a)$ средней мощности излучения и $(b)$ коэффициента поглощения свободными носителями в структурах с разным количеством квантовых ям: $1-4,2-6$, $3-8,4-10$ Кя.

При этом населенность волноводного слоя уменьшается с увеличением числа квантовых ям. Так, изменение числа квантовых ям с четырех до шести дает значительный выигрыш в мощности и снижении внутренних потерь (рис. 4). Последующее увеличение количества квантовых ям до 10 дает лишь небольшое улучшение характеристик, которое может стать еще менее заметным из-за ухудшения оптических и структурных свойств активной области ввиду большего числа выращиваемых полупроводниковых слоев.

\section{6. Заключение}

Таким образом, показано, что увеличение числа квантовых ям в активной области гетеролазера со значительным вытеканием излучения через подложку, с одной стороны, приводит к неравномерному распределению носителей заряда в активной среде, с другой - способствует уменьшению населенности волноводного слоя и снижению внутренних оптических потерь. Установлено, что конструкции лазеров со значительным вытеканием излучения в подложку, включающие 6-8 квантовых ям в активной области, являются оптимальными как для начала лазерной генерации, так и для увеличения выходной оптической мощности лазеров. Наблюдаемые эффекты фотолюминесценции, обусловленные изменением количества квантовых ям в активной области, можно рассматривать как способ предварительной диагностики оптического качества лазерных структур.

Работа выполнена при поддержке стипендии президента Российской Федерации молодым ученым и аспирантам, осуществляющим перспективные научные исследования и разработки по приоритетным направлениям модернизации российской экономики № СП-109.2016.3 и частичной поддержке Министерства образования и науки России (государственное задание 3.285.2014/К).

\section{Список литературы}

[1] С.М. Некоркин, Б.Н. Звонков, М.Н. Колесников, Н.В. Дикарева, В.Я. Алешкин, А.А. Дубинов. Вестн. ННГУ, 1 (1), 30 (2012).

[2] А.А. Бирюков, С.М. Некоркин, М.Н. Колесников, Т.С. Бабушкина, В.Я. Алешкин, А.А. Дубинов. ЖТФ, 81 (7), 149 (2011).

[3] С.М. Некоркин, Б.Н. Звонков, М.В. Карзанова, Н.В. Дикарева, В.Я. Алешкин, А.А. Дубинов. Квант. электрон., 42 (10), 931 (2012).

[4] Н.Л. Баженов, К.Д. Мынбаев, В.И. Иванов-Омский, В.А. Смирнов, В.П. Евтихиев, Н.А. Пихтин, М.Г. Растегаева, А.Л. Станкевич, И.С. Тарасов, А.С. Школьник, Г.Г. Зегря. ФТП, 39 (10), 1252 (2005).

[5] А.А. Афоненко, Д.В. Ушаков. ФТП, 48 (1), 88 (2014).

[6] A.R. Adams, D.J. Dunstan, E.P. O'Reilly. Physica Scripta T, 39, 196 (1991).

[7] С.М. Некоркин, М.В. Карзанова, Н.В. Дикарева, Б.Н. Звонков, В.Я. Алешкин. Письма ЖТФ, 40 (10), 52 (2014).

[8] Д.В. Ушаков, А.А. Афоненко, В.Я. Алешкин. Квант. электрон., 43 (11), 999 (2013).

Редактор А.Н. Смирнов

\section{Effect of the active region „volume“ on radiative properties of laser heterostructures with radiation coupling-out through substrate}

S.M. Nekorkin ${ }^{1}$, B.N. Zvonkov' ${ }^{1}$, N.V. Baidus ${ }^{1}$, N.V. Dikareva ${ }^{1}$, O.V. Vikhrova ${ }^{1}$, A.A. Afonenko ${ }^{2}$, D.V. Ushakov ${ }^{2}$

${ }^{1}$ Physicotechnical Research Institute,

Nizhny Novgorod State University, 603950 Nizhny Novgorod, Russia

2 Belarusian State University, 220030 Minsk, Republic of Belarus

Abstract Radiative properties of $\mathrm{InGaAs} / \mathrm{GaAs} / \mathrm{InGaP}$ laser structures with radiation streaming through the substrate with different number of quantum wells in the active region and laser diodes based on them were studied. It has been established that the 6-8 quantum well in active region are optimal in terms of threshold current and the optical output power of laser diodes. 